\title{
Efeito do fracionamento da ração diária sobre a concentração sérica de progesterona em porcas gestantes
}

[Effect of fractionating daily food intake on serum progesterone concentration in pregnant sows]

\author{
L.F.R. Carvalho ${ }^{1}$, J.M. Silva Filho ${ }^{1}$, I.J. Silva ${ }^{1}$, M.N. Bandeira ${ }^{1}$, M.P. Morais ${ }^{2}$, M.S. Palhares ${ }^{1}$ \\ ${ }^{1}$ Escola de Veterinária da UFMG \\ Caixa Postal 567 \\ 30123-970 - Belo Horizonte, MG \\ ${ }^{2}$ DB Melhoramento Suíno, Patos de Minas, MG
}

Recebido para publicação em 25 de novembro de 2002

Recebido para publicação, após modificações, em 29 de setembro de 2003

*Autor para correspondência

E-mail: monteiro@vet.ufmg.br

\section{RESUMO}

Avaliou-se a influência do fracionamento da alimentação diária nos primeiros 30 dias de gestação de porcas sobre a concentração sérica de progesterona $(\mathrm{ng} / \mathrm{ml})$ no $3^{\circ}, 5^{\circ}, 8^{\circ}, 12^{\circ}, 21^{\circ}$ e $28^{\circ}$ dias pós-cobrição, utilizando-se a técnica de radioimunoensaio, a partir de amostras de sangue coletadas da veia cava em 15 matrizes entre o terceiro e o sexto parto. As fêmeas foram distribuídas em três grupos de cinco animais: o grupo 1 recebeu apenas um trato diário de dois quilos de ração, o grupo 2 recebeu dois tratos diários de um quilo de ração cada, e o grupo 3, três tratos diários de 670 gramas de ração até 30 dias de gestação. O fracionamento da quantidade de ração fornecida diariamente não alterou a concentração sérica de progesterona até o $28^{\circ}$ dia de gestação nas matrizes suínas pluríparas.

Palavras-chave: suínos, progesterona, gestação, ração

\begin{abstract}
The influence of fractionating daily food intake from $1^{\text {st }}$ to $30^{\text {th }}$ days of pregnancy, on serum progesterone concentrations $(\mathrm{ng} / \mathrm{ml})$ in multiparous sows was evaluated on $3^{\text {rd }}, 5^{\text {th }}, 8^{\text {th }}, 12^{\text {th }}, 21^{\text {th }}$ and $28^{\text {th }}$ days after insemination. The progesterone concentrations were determined by radioimmunoassay (RIA) from blood samples collected from cava vein in 15 sows between the third and the sixth parturition. The sows were distributed into three groups of five animals each. One group was treated once a day with $2.0 \mathrm{~kg}$ of ration (T1); a second group was treated twice a day with $1.0 \mathrm{~kg}$ of ration (T2); and a third group was treated three times a day with 670 grams of ration (T3) for 30 days during pregnancy. No effects of fractionating daily food intake on serum progesterone concentrations were observed.
\end{abstract}

Keywords: swine, progesterone, pregnancy, ration

\section{INTRODUÇÃO}

A influência da concentração energética no período inicial de gestação sobre a sobrevivência embrionária tem sido estudada em fêmeas suínas (Dick et al., 1980; Ashworth, 1991; Jindal et al., 1997). Entretanto o manejo alimentar e suas implicações em características reprodutivas só recentemente começaram a ser estudados em bovinos (Vasconcelos, 1998) e suínos (Bandeira, 1999). 
Vasconcelos (1998) em dois experimentos, avaliou a relação entre o horário de fornecimento e a quantidade de alimento ingerido sobre a concentração sérica de progesterona endógena e também sobre a concentração sérica de progesterona exógena em vacas leiteiras de alta produção. No primeiro experimento observou redução da concentração de progesterona sérica nos grupos tratados menos vezes ao dia. No tratamento associado ao maior número de tratos por dia, observou concentração sérica de progesterona mais constante. No segundo, avaliando o oferecimento ou não de ração completa sobre a variação da concentração sérica de progesterona exógena, após eliminação do corpo lúteo, verificou maior concentração sérica de progesterona no grupo em jejum em relação ao grupo alimentado $(4,8 \mathrm{ng} / \mathrm{ml}$ e 4,3ng/ml, respectivamente). Como resultado o autor recomendou maior número de tratos diários para vacas de alta produção, sugerindo que maior fluxo hepático e conseqüente maior "clearance" da progesterona circulante acontecem em vacas com maior ingestão de matéria seca por trato.

Bandeira (1999), ao avaliar o efeito do fracionamento da ração diária em um, dois ou três tratos de matrizes suínas, no período de 30 dias após o dia da terceira inseminação, sobre o número de leitões nascidos e a taxa de parto, não observou alterações nessas características.

O objetivo deste trabalho foi avaliar o efeito do fracionamento da ração diária sobre a concentração sérica de progesterona até 28 dias de gestação de fêmeas pluríparas suínas.

\section{MATERIAL E MÉTODOS}

O experimento foi realizado entre 8 de agosto e 8 de setembro em uma granja multiplicadora de matrizes suínas, localizada no município de Patos de Minas, MG.

Foram utilizadas 15 fêmeas híbridas do terceiro ao sexto parto, cobertas na mesma semana, com peso médio de 255,93 $\pm 27,55 \mathrm{~kg}$ e intervalo desmama-cio de 96 horas. As fêmeas desmamaram seus leitões, em média, quando eles estavam com 19 dias de idade, no final da lactação e antes do início dos tratamentos. A desmama ocorreu sempre às quintas-feiras pela manhã, quando as porcas, levadas para o galpão de gestação, foram distribuídas aleatoriamente entre os tratamentos e mantidas em gaiolas individuais. A rufiação das fêmeas, com cachaços adultos e de boa libido, iniciou-se sempre às quintas-feiras, no turno da tarde, feita duas vezes ao dia, à tarde e pela manhã, e consistiu de passagem do macho em frente às gaiolas e pressão no dorso das fêmeas. As inseminações foram realizadas 12 horas após o início do cio e repetidas 24 e 36 horas após, sempre na presença do cachaço. As doses inseminantes, preparadas no laboratório da própria granja, foram armazenadas por no máximo 48 horas.

As matrizes, divididas em três grupos de cinco animais cada, foram submetidas a três diferentes formas de arraçoamento diário até 30 dias de gestação (três tratamentos, cinco repetições), utilizando-se uma ração de gestação (Tab. 1). A distribuição dos animais nos tratamentos (T) foi feita por linhagem e ordem de parto. No T1, as fêmeas receberam dois quilogramas de ração às sete horas; no T2, um quilograma de ração às sete horas e outro às 20 horas; no T3, 0,670 quilograma de ração às sete, 12 e 20 horas.

Amostras de sangue foram coletadas no $3^{\circ}, 5^{\circ}, 8^{\circ}, 12^{\circ}, 21^{\circ}$ e $28^{\circ}$ dias após a terceira inseminação por punção da veia cava (Muirhead, Alexander, 1997), estocadas em tubos de ensaio de 10ml (suspensos sobre o gelo em caixa de isopor por 10 minutos para formação de coágulo sangüíneo e retirada do soro) e congeladas à $-22^{\circ} \mathrm{C}$. A dosagem da concentração sérica de progesterona foi feita pela técnica de radioimunoensaio (RIA) de fase sólida, utilizando um conjunto comercial (Coat-a-Count ${ }^{\circledR}$ Progesterone KIT, DPC-Medlab) em contador de cintilação de radiação gama ${ }^{2}$, realizada no laboratório de biofísica do Instituto de Ciências Biológicas da Universidade Federal de Minas Gerais. 
Tabela 1. Composição da ração de gestação para fêmeas suínas

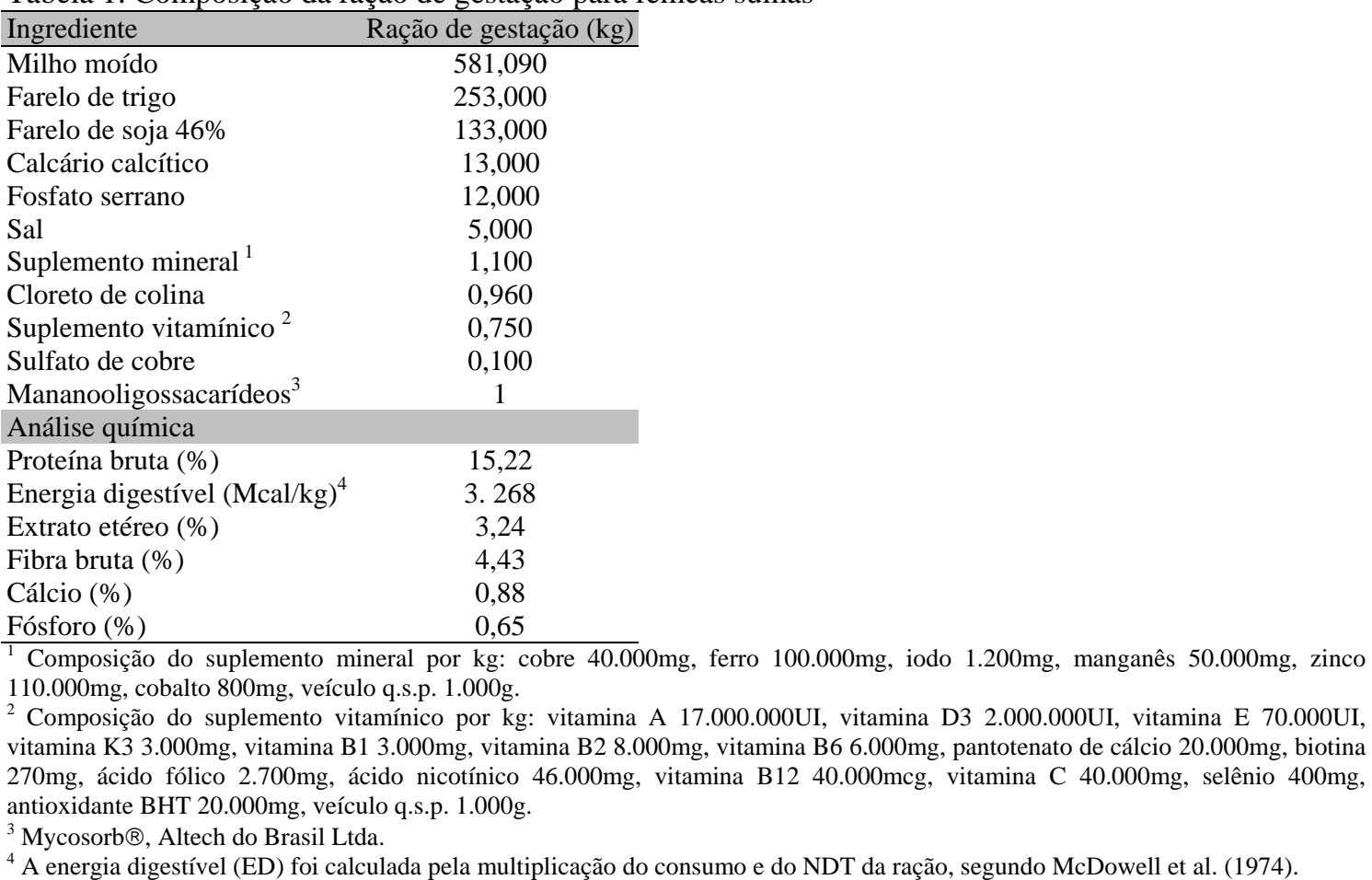

Foram incluídas variáveis em relação à condição corporal (peso, escore corporal e espessura de toucinho) e ao desempenho reprodutivo (taxa de gestação, descarte, taxa de parto, nascidos totais, nascidos vivos, natimortos, mumificados e peso da leitegada ao nascer). As medidas de peso corporal, espessura de toucinho e o escore corporal foram feitas no início dos tratamentos (peso1, ET1 e EC1), aos 30 dias (peso2, ET2 e EC2) e aos 110 dias de gestação (peso3, ET3 e EC3). Para mensuração da espessura de toucinho utilizou-se aparelho de ultrasom (SNK, Pig Scan, Sonda MB 4S) sobre o ponto $\mathrm{P}_{2}$ preconizado por Roppa (1991).

Para avaliação do escore corporal utilizou-se a classificação proposta por Chacon (1991).

As características produtivas peso e espessura de toucinho, as reprodutivas número total de nascidos, número de nascidos vivos e peso total da leitegada, e a concentração sérica de progesterona foram submetidas à análise de variância, e as diferenças entre médias aos testes Student e Student-NewmanKeuls (Sampaio, 1998). Para avaliação do efeito dos tratamentos sobre o escore corporal foi utilizado o teste Kruskal-Wallis (Sampaio, 1998). As médias foram comparadas pelos testes SNK e Kruskal-Wallis usando-se o Sistema de Análises Estatísticas 7.0 (Sistema..., 1997) As características reprodutivas taxa de parto, taxa de parto ajustada, taxa de corrimento, taxa de gestação aos 30 dias, taxa de aborto, taxa de natimortos e mumificados foram submetidas ao teste do qui-quadrado (Sampaio, 1998).

\section{RESULTADOS E DISCUSSÃO}

Os dados de peso, escore corporal e espessura de toucinho obtidos à cobertura, aos 30 dias e aos 110 dias de gestação são apresentados na Tab. 2.

Não houve diferença entre tratamentos quanto ao peso, escore corporal e espessura de toucinho. As fêmeas apresentaram redução de peso corporal do início do experimento até 30 dias de gestação, 
255,93kg para 248,46kg. Bandeira (1999) também observou resultados semelhantes no mesmo rebanho, cuja redução foi de $233,27 \mathrm{~kg}$ para $224,27 \mathrm{~kg}$. O resultado é considerado indesejável, mesmo levando-se em consideração a restrição alimentar recomendada pelo NRC (1998) e imposta aos animais no início da gestação.

Quanto à concentração sérica de progesterona entre o $3^{\circ}$ e $28^{\circ}$ dia de gestação (Tab. 3), não houve diferença $(\mathrm{P}>0,05)$ entre os tratamentos. Uma matriz do tratamento 3 foi retirada do experimento por ter retornado ao cio no $21^{\circ}$ dia pós-inseminação.

Tabela 2. Peso corporal, espessura de toucinho e escore corporal de fêmeas suínas segundo o tratamento

\begin{tabular}{|c|c|c|c|c|c|}
\hline \multirow{2}{*}{ Característica } & \multicolumn{5}{|c|}{ Tratamento } \\
\hline & & $\mathrm{T} 1$ & $\mathrm{~T} 2$ & T3 & Média \\
\hline Peso1 (kg) & $\begin{array}{c}(\overline{\mathrm{x}} \pm \mathrm{s}) \\
(\mathrm{n})\end{array}$ & $\begin{array}{c}245,00 \pm-21,22 \\
5\end{array}$ & $\begin{array}{c}273,00 \pm 21,52 \\
5\end{array}$ & $\begin{array}{c}249,80 \pm 34,39 \\
5\end{array}$ & $\begin{array}{c}255,93 \pm 27,55 \\
15\end{array}$ \\
\hline Escore1 & $\begin{array}{l}(\bar{x} \pm s) \\
(n)\end{array}$ & $\begin{array}{c}2,60 \pm 0,55 \\
5\end{array}$ & $\begin{array}{c}2,60 \pm 0,55 \\
5\end{array}$ & $\begin{array}{c}3,40 \pm 0,55 \\
5\end{array}$ & $\begin{array}{c}2,87 \pm 0,64 \\
15\end{array}$ \\
\hline $\begin{array}{l}\text { Espessura de } \\
\text { toucinho } 1(\mathrm{~mm})\end{array}$ & $\begin{array}{l}(\bar{x} \pm s) \\
(n)\end{array}$ & $\begin{array}{c}16,20 \pm 3,49 \\
5\end{array}$ & $\begin{array}{c}16,80 \pm 0,45 \\
5\end{array}$ & $\begin{array}{c}14,60 \pm 2,41 \\
5\end{array}$ & $\begin{array}{c}15,87 \pm 2,47 \\
15\end{array}$ \\
\hline Peso2 (kg) & $\begin{array}{l}(\bar{x} \pm s) \\
(\mathrm{n})\end{array}$ & $\begin{array}{c}236,40 \pm 20,48 \\
5\end{array}$ & $\begin{array}{c}271,50 \pm 22,49 \\
4\end{array}$ & $\begin{array}{c}243,20 \pm 34,77 \\
5\end{array}$ & $\begin{array}{c}248,86 \pm 29,11 \\
14\end{array}$ \\
\hline Escore2 & $\begin{array}{c}(\overline{\mathrm{x}} \pm \mathrm{s}) \\
(\mathrm{n})\end{array}$ & $\begin{array}{c}3,20 \pm 0,45 \\
5\end{array}$ & $\begin{array}{c}3,25 \pm 0,50 \\
4\end{array}$ & $\begin{array}{c}3,20 \pm 0,45 \\
5\end{array}$ & $\begin{array}{c}3,21 \pm 0,43 \\
14\end{array}$ \\
\hline $\begin{array}{l}\text { Espessura de } \\
\text { toucinho } 2(\mathrm{~mm})\end{array}$ & $\begin{array}{l}(\bar{x} \pm s) \\
(n)\end{array}$ & $\begin{array}{c}17,80 \pm 3,42 \\
5\end{array}$ & $\begin{array}{c}19,00 \pm 1,41 \\
4\end{array}$ & $\begin{array}{c}18,60 \pm 2,19 \\
5\end{array}$ & $\begin{array}{c}18,43 \pm 2,41 \\
14\end{array}$ \\
\hline Peso3 (kg) & $\begin{array}{l}(\bar{x} \pm s) \\
(n)\end{array}$ & $\begin{array}{c}268,40 \pm 18,15 \\
5\end{array}$ & $\begin{array}{c}306,25 \pm 17,50 \\
4\end{array}$ & $\begin{array}{c}278,75 \pm 17,02 \\
4\end{array}$ & $\begin{array}{c}283,23 \pm 23,10 \\
13)\end{array}$ \\
\hline Escore3 & $\begin{array}{c}(\overline{\mathrm{x}} \pm \mathrm{s}) \\
(\mathrm{n})\end{array}$ & $\begin{array}{c}3,20 \pm 0,45 \\
5\end{array}$ & $\begin{array}{c}3,50 \pm 0,58 \\
4\end{array}$ & $\begin{array}{c}3,50 \pm 0,58 \\
4\end{array}$ & $\begin{array}{c}3,38 \pm 0,51 \\
13\end{array}$ \\
\hline $\begin{array}{l}\text { Espessura de } \\
\text { toucinho } 3(\mathrm{~mm})\end{array}$ & $\begin{array}{c}(\bar{x} \pm s) \\
(n)\end{array}$ & $\begin{array}{c}20,60 \pm 2,30 \\
5\end{array}$ & $\begin{array}{c}21,75 \pm 2,63 \\
4\end{array}$ & $\begin{array}{c}21,25 \pm 1,26 \\
4\end{array}$ & $\begin{array}{c}21,15 \pm 2,03 \\
13\end{array}$ \\
\hline
\end{tabular}

Tabela 3. Concentração sérica de progesterona (ng/ml) de acordo com o dia de coleta e o tratamento, em fêmeas suínas

\begin{tabular}{lcccc}
\hline \multirow{2}{*}{ Dia de coleta } & \multicolumn{4}{c}{ Tratamento } \\
\cline { 2 - 5 } & T 1 $(\mathrm{n}=5)$ & T 2 $(\mathrm{n}=5)$ & $\mathrm{T} \mathrm{3}(\mathrm{n}=4)$ & Média $(\mathrm{n}=14)$ \\
\hline 3 & $9,10 \pm 2,01 \mathrm{C}$ & $10,80 \pm 3,17 \mathrm{C}$ & $13,00 \pm 1,83 \mathrm{D}$ & $10,82 \pm 2,78$ \\
8 & $17,00 \pm 3,39 \mathrm{~B}$ & $17,40 \pm 2,19 \mathrm{~B}$ & $19,00 \pm 1,83 \mathrm{C}$ & $17,71 \pm 2,55$ \\
12 & $19,80 \pm 5,68 \mathrm{~B}$ & $20,40 \pm 3,21 \mathrm{~B}$ & $24,75 \pm 3,86 \mathrm{AB}$ & $21,43 \pm 4,62$ \\
21 & $28,80 \pm 4,55 \mathrm{~A}$ & $29,00 \pm 3,00 \mathrm{~A}$ & $28,75 \pm 3,95 \mathrm{~A}$ & $28,86 \pm 3,57$ \\
28 & $22,00 \pm 2,74 \mathrm{~B}$ & $23,20 \pm 4,87 \mathrm{~B}$ & $18,50 \pm 2,38 \mathrm{C}$ & $21,43 \pm 3,86$ \\
\hline
\end{tabular}

Médias seguidas por letras diferentes dentro da mesma coluna diferem (SNK, $\mathrm{P}<0,05)$ entre si.

$\mathrm{T} 1=$ ração fornecida às $7 \mathrm{~h} ; \mathrm{T} 2=$ ração fornecida às 7 e às $20 \mathrm{~h}$; $\mathrm{T} 3=$ ração fornecida às 7,12 e $20 \mathrm{~h}$.

Na literatura consultada a concentração sangüínea de progesterona na fase inicial de gestação foi avaliada em marrãs (Archbong et al., 1987; Ashworth et al., 1994). O emprego de fêmeas pluríparas possivelmente justifica os valores médios de progesterona mais elevados deste experimento. Sabe-se que as pluríparas apresentam taxa de ovulação mais alta do que marrãs (van der Lende, Schoenmaker,1990), conseqüentemente, maior concentração de progesterona, relacionada ao maior número de corpos lúteos (Staigmiller, 1974, apud Gordon, 1997). Observou-se aumento da concentração plasmática de 
Efeito do fracionamento da ração diária...

progesterona desde o $3^{\circ}$ dia pós-inseminação, pico entre o $12^{\circ}$ e o $21^{\circ}$ dia e queda, não muito acentuada, a partir do $21^{\circ}$ dia pós-inseminação (Fig. 1).

A curva da concentração de progesterona é semelhante à de outros trabalhos (Archbong et al., 1987; Ashworth et al., 1994). A regressão da variável dependente concentração sérica de progesterona (PROG) em relação ao dia de coleta (DIA) resultou na seguinte equação: PROG= -4,84650+6,32865(DIA) $0,381668(\text { DIA })^{2}+0,00674862(\text { DIA })^{3}, R^{2}=0,63(P<0,0001)$.

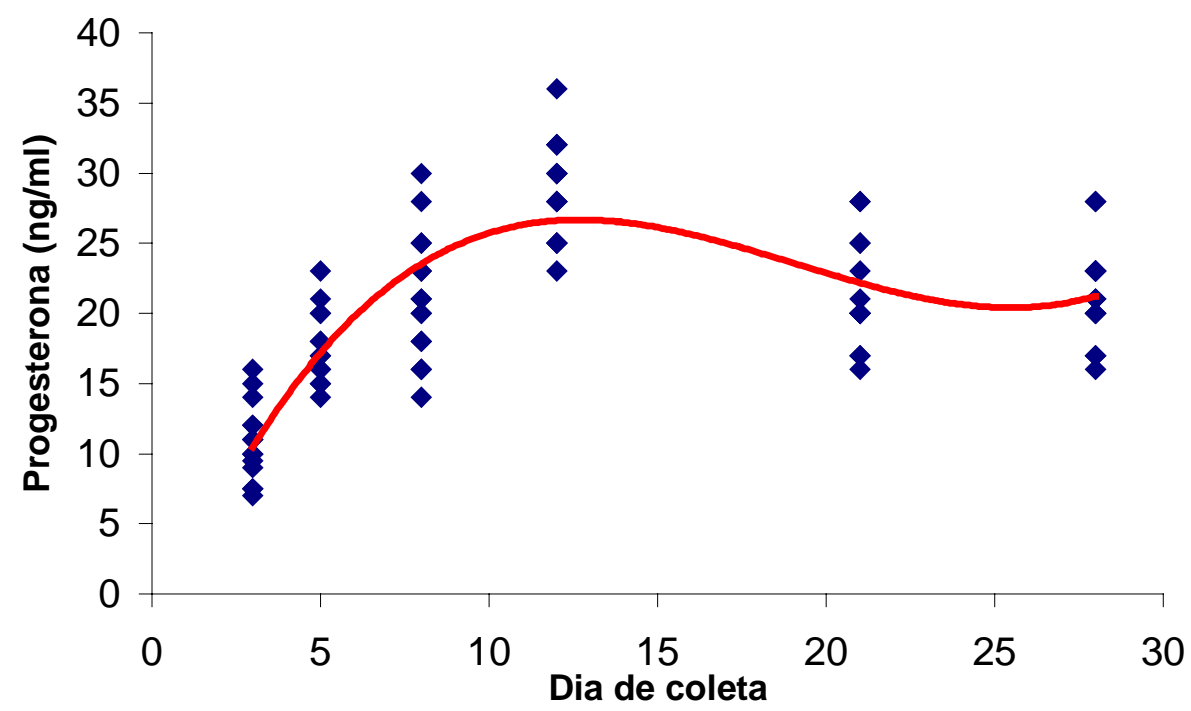

Figura 1. Concentração sérica de progesterona em função do dia de coleta em fêmeas suínas.

O valor de $\mathrm{R}^{2}$ mostra ser o dia de coleta fator preponderante no resultado final da concentração sérica de progesterona.. A distribuição dos dados em seus respectivos dias mostrou-se homogênea, com o ápice da curva entre o $12^{\circ}$ e o $21^{\circ}$ dia pós-cobrição.

Diferenças na concentração de progesterona circulante atribuídas ao excesso de energia na ração no início da gestação foram observadas por Dick et al. (1980) e Jindal et al. (1996) em experimentos com marrãs. Prime et al. (1988), ao estudarem porcas pluríparas, não observaram diferenças na concentração de progesterona em fêmeas submetidas a tratos com diferentes quantidades de ração.

O desempenho reprodutivo das fêmeas está sumarizado na Tab. 4. 
Tabela 4. Desempenho reprodutivo de fêmeas suínas segundo o tratamento

\begin{tabular}{|c|c|c|c|c|c|}
\hline Característica & & T1 & $\mathrm{T} 2$ & T3 & Média \\
\hline \multirow{2}{*}{$\begin{array}{l}\text { Taxa de gestação } \\
\text { aos } 30 \text { dias }\end{array}$} & $(\%)$ & 100,00 & 100,00 & 80,00 & 97,08 \\
\hline & (n) & 5 & 5 & 4 & 14 \\
\hline \multirow{2}{*}{ Descarte } & $(\%)$ & 0,00 & 20,00 & 0,00 & 6,66 \\
\hline & (n) & 0 & 1 & 0 & 1 \\
\hline \multirow{2}{*}{ Taxa de parto } & (\%) & 100,00 & 80,00 & 80,00 & 86,66 \\
\hline & (n) & 5 & 4 & 4 & 13 \\
\hline \multirow{2}{*}{ Taxa de parto ajustada } & (\%) & 100,00 & 100,00 & 80,00 & 92,86 \\
\hline & (n) & 5 & 4 & 4 & 13 \\
\hline Nascidos totais (n) & $(\bar{x} \pm s)$ & $12,00 \pm 3,61$ & $12,50 \pm 3,70$ & $12,75 \pm 2,63$ & $12,38 \pm 3,10$ \\
\hline Nascidos vivos (n)s & $(\bar{x} \pm s)$ & $11,00 \pm 3,00$ & $12,25 \pm 3,20$ & $12,50 \pm 3,11$ & $11,85 \pm 3,10$ \\
\hline \multirow{2}{*}{ Natimortos } & $(\%)$ & 6,66 & 2,00 & 1,96 & 2,48 \\
\hline & (n) & $4 / 60$ & $1 / 50$ & $1 / 51$ & $4 / 161$ \\
\hline \multirow{2}{*}{ Mumificados } & $(\%)$ & 1,67 & 0,00 & 0,00 & 0,62 \\
\hline & (n) & $1 / 60$ & $0 / 50$ & $0 / 51$ & $1 / 161$ \\
\hline Peso da leitegada (kg) & $(\bar{x} \pm s)$ & $16,90 \pm 1,95$ & $22,63 \pm 1,70$ & $21,00 \pm 5,60$ & $19,92 \pm 4,06$ \\
\hline
\end{tabular}

T1= ração fornecida às 7h; T2=ração fornecida às 7 e às 20 h; T3= ração fornecida às 7, 12 e 20h.

O desempenho reprodutivo está dentro do esperado segundo as observações de Sesti e Sobestiansky (1998), com exceção das taxas de fertilidade e repetição de cio do tratamento 3 e do número de natimortos e mumificados do tratamento 1, cujos valores estão elevados. Neste experimento, nenhuma fêmea apresentou descarga vulvar ou abortou. Bandeira (1999), utilizando o fracionamento da ração no início da gestação de matrizes suínas, observou taxa de parto de 93,9\%, com número total de nascidos de 11,59 leitões por leitegada. Segundo o autor, a porcentagem de natimortos e mumificados foi alta, possivelmente, por estar associada ao grande número de nascidos.

Neste experimento não houve efeito dos tratamentos $(\mathrm{P}>0,05)$ sobre a concentração sérica de progesterona. Possivelmente os resultados não significativos quanto à concentração de progesterona sérica e ao desempenho reprodutivo se devam à restrição alimentar a que estes animais foram submetidos no início da gestação, aspecto já mencionado por Ludke et al. (1998). Esse fato não acontece com vacas de alta produção, submetidas a alimentação altamente energética distribuída de forma fracionada (Vasconcelos, 1998). Esse autor observou redução na concentração de progesterona sangüínea de animais que receberam menor número de tratos diários. Em suínos, os efeitos da alimentação sobre a reprodução são mais evidentes em animais com concentração baixa de progesterona (Pharazyn et al., 1991), e manifestam-se mais em marrãs (Ashworth, 1991) do que em matrizes pluríparas (Toplis et al., 1983).

\section{CONCLUSÃO}

A concentração sérica de progesterona em fêmeas suínas pluríparas não foi alterada pelas formas de arraçoamento usadas neste trabalho.

\section{REFERÊNCIAS BIBLIOGRÁFICAS}

ARCHIBONG, A.E.; ENGLAND, D.C.; STORMSHACK, F. Factors contributing to early embrionic mortality in gilts bred at first estrus. J. Anim. Sci., v.64, p.474-478, 1987.

ASHWORTH, C.J. Effect of pre-mating nutritional status and post-mating progesterone supplementation on embryo survival and conceptus growth in gilts. Anim. Reprod. Sci., v.26, p.311-321, 1991. 
ASHWORTH, C.J.; ROSS, A.W.; HALEY, C.S. Comparisons between peripheral progesterone concentrations in cyclic and pregnant Landrace x Large White and Meishan gilts. Reprod. Fertil. Dev., v.6, p.777-782, 1994.

BANDEIRA, M.N. Fracionamento da alimentação diária na fase inicial de gestação e desempenho reprodutivo de fêmeas suínas. 1999. 85p. Dissertação (Mestrado)- Escola de Veterinária, Universidade Federal de Minas Gerais, Belo Horizonte.

CHACON, H.L.A. Efeito da ocitocina e neostigmina, associadas ou não ao sulfato de sódio, sobre a natimortalidade na espécie suína.1991. 62p. Dissertação (Mestrado)- Escola de Veterinária, Universidade Federal de Minas Gerais, Belo Horizonte.

DICK, G.W.; PALMER, W.M.; SIMARAKS, S. Progesterone and luteinizing hormone concentration in serum of pregnant gilts on different levels of feed consumption. Can. J. Anim. Sci., v.60, p.877- 884, 1980.

GORDON, I. Pregnancy testing in pigs. In: Reproduction in pigs. Oxon: Cab International, 1997. Cap.4, p.94-114. 247p.

JINDAL, R.; COSGROVE, J.R.; AHERNE, F.X. et al. Effect of nutrition on embryonal mortality in gilts: association with progesterone. J. Anim. Sci., v.74, p. 620-624, 1996.

JINDAL, R.; COSGROVE, J.R.; FOXCROFT, G.R. Progesterone mediates nutritionally induced effects on embryonic survival in gilts. J. Anim. Sci., v.75, p.1063-1070, 1997.

LUDKE, J.V.; BERTOL, T.M.; SCHEURMANN, G.N. Manejo da alimentação. In: Suinocultura intensiva. Brasília: Serviço de Produção de Informação, 1998. Cap.4, p.65-90. 388p.

McDOWELL, L.R; CONRAD, J.H.; THOMAS, J.E. et al. Latin American tables of feed composition, 1974. 509p.

MUIRHEAD, M.R.; ALEXANDER, T.J.L. Reproduction: non infectious infertility. In: Managing pig health and the treatment of disease, 1997. Cap.5, p.163-164. 608p.

NUTRIENT requirements of swine. 19.ed. Washington: National Academic Press, 1998. 192p.

PHARAZYN, A.; DEN HARTOG, L.A.; FOXCROFT, G.R. et al. Dietary protein intake, plasma progesterone and embryo survival in early pregnancy in the gilt. Can. J. Anim. Sci., v.71, p.949-952, 1991.

PRIME, G.R.; VARLEY, M.A.; SYMONDS, H.W. The effect of food intake during lactation and early pregnancy on plasma progesterone concentrations and prolificacy in multiparous sows. Anim. Prod., v.46, p.499, 1988.

ROPPA, L.A. A nutrição e a alimentação da fêmea reprodutoras. In: CONGRESSO BRASILEIRO DE REPRODUÇÃO ANIMAL, 9, 1991, Belo Horizonte. Anais... Belo Horizonte: CBRA, 1991. p.217-247.

SAMPAIO, I.B.M. Estatística aplicada à produção animal. Belo Horizonte: UFMG, 1998. 221p.

SESTI, L.A.C.; SOBESTIANSKY, J. Aspectos da produtividade. In: SOBESTIANSKY, J.; WENTZ, I., SILVEIRA, P.R.S. et al. Suinocultura intensiva. Brasília: Serviço de Produção de Informação, 1998. Cap.4, p.65-90. 388p.

TOPLIS, P.; GINESI, M.F.; WRATHALL, A. E. The influence of high food levels in early pregnancy on embryo survival in multiparous sows. Anim. Prod., v.37, p.45-48, 1983.

SISTEMA de análises estatísticas e genéticas - SAEG, Viçosa, UFV, 1995

van der LENDE, T.; SCHOENMAKER, G.J.W. The relationship between rate and litter size before and after day 35 of pregnance in gilts and sows: an analysis of published data. Livest. Prod. Sci., v.26, p.217229, 1990. 


\section{Carvalho et al.}

VASCONCELOS, J.L.M. Avaliação da sincronização de ovulações e de fatores relacionados com a produção de leite e taxa de concepção em vacas. 1998. 115p. Tese (Doutorado). Faculdade de Ciências Agrárias e Veterinárias, UNESP, Jaboticabal, SP. 